\title{
A Learner Model for Adaptable e-Learning
}

\author{
Moiz Uddin Ahmed \\ Department of Computer Science \\ Allama Iqbal Open University \\ Islamabad, Pakistan
}

\author{
Nazir Ahmed Sangi \\ Department of Computer Science \\ Allama Iqbal Open University \\ Islamabad, Pakistan
}

\author{
Amjad Mahmood \\ Department of Computer Science \\ University of Bahrain \\ Bahrain
}

\begin{abstract}
The advancement in Information and Communication Technology (ICT) has provided new opportunities for teaching and learning in the form of e-learning. However, developing specialized contents, accommodating profiles of learners, e-learning pedagogy and available ICT infrastructure are the real challenges that need to be properly addressed for any successful e-learning system. The adaptability in an e-learning system can be used to address many of these challenges and issues. This paper proposes a learner model for adaptable e-learning model. The proposed model is based on the findings of a survey conducted to investigate the profiles and preferences of the local learners. The conceptual framework highlights the layered model of adaptable e-learning with the knowledge level of learners as the foundation layer. The foundation layer is derived from four components of adaptable elearning, i.e., domain, program pedagogy, student model and technology interface. The learner algorithm retrieves the adaptable contents from the domain model by analyzing the learner information stored in the student model. The eassessment is part of the program pedagogy and the assessment results are used to control the presentation and navigation of adaptable contents during the learning process. The model has been tested on a Computer Science course offered by Allama Iqbal Open University, Islamabad, Pakistan at Post Graduate Diploma level. The results show that the proposed adaptable elearning model has significantly improved the knowledge level of the learners.
\end{abstract}

Keywords-E-learning; adaptable; pedagogy; learning styles; e-assessment

\section{INTRODUCTION}

E-learning refers to electronic means of education through the use of computers, Internet and media technologies [1]. In recent years, e-learning has become more popular [2]-[4] and its use in educational sector, especially in distance education, is increasing [5]. But at the same time, e-learning is posing many challenges because most of the e-learning systems provide teaching rather than learning [6]. Therefore, there is a need to build e-learning models that are adaptable, interactive and localized.

Localization is the process of adapting e-learning functional properties and content presentation to accommodate the needs and requirements of local learners [7]. The localized applications need to be built upon the international e-learning standards in order to get technology acceptance by local learners and teachers [8]. Adaptivity under localized conditions creates more effective learning scenarios by focusing on the needs and learning styles of individual students [9]. It provides appropriate lessons to a learner, when needed. According to Brusilovsky [10], adaptivity is significant for e-learners because they might differ in their strengths and weaknesses while grasping a knowledge concept. It can tailor a learning path based on their needs, requirements and learning styles [11].

The development of specialized e-learning models is a real challenge in distant learning environment for a developing country like Pakistan. Various issues such as development of specialized contents suitable for local learners and its delivery under local ICT infrastructure should be properly addressed [12]-[13]. The major contribution of this research is development of an adaptable e-learning model that not only fulfills the needs of localized environment but is also in compliance with international standards such as IEEE Learning Object Metadata (LOM) and IMS Learner Information Package (LIP). The theoretical models are explored to derive the important parameters of adaptable e-learning. A unique instructional pedagogy has been implemented that converts the teaching approaches into sequence of learning activities. An algorithm has been proposed for content presentation and navigation control. The delivery and communication tools of MOODLE Learning Management System (LMS) are used to implement the proposed adaptable model.

The rest of the paper is organized as: Section II presents the literature review, Section III discusses e-learning survey results conducted from the students of Allama Iqbal Open University (AIOU), Section IV presents the proposed adaptive model and discusses its major components, and Section $\mathrm{V}$ presents the experimental results followed by conclusions in Section VI.

\section{LITERATURE REVIEW}

Early e-learning systems used computers as self-contained teaching machines in order to provide instructional support to a group of learners [14]. However, these systems were lacking in analyzing the needs of a particular student; and therefore were unable to provide personalized assistance [15]. As computer technology became more advanced, researchers began to think about the development of more advanced and innovative learning systems in the form of adaptive e-learning [16]. Brusilovsky and Miller [17] divided adaptive e-learning systems into two major categories: Intelligent Tutoring Systems (ITS) and Adaptive Hypermedia (AH). Intelligent Tutoring Systems are specialized learning systems which facilitate the process of learning based on individual student's needs. They are problem-specific and provide alternate instruction methods [18]. Adaptive Hypermedia works along intersection of hypertext (hypermedia) and user modeling. They are curriculum specific, focus on course modules and construct a model of users based on their personality, 
interaction and attitudes [19]. While developing adaptive systems there is an important aspect that "what can be adapted?" The literature review provides the answer by denoting the classes of adaptive presentation and adaptive navigation. The adaptive presentation displays contents on hypermedia. The techniques of adaptive presentation are adaptive text presentation, adaptive multimedia presentation and adaptation of modality. On the other hand adaptive navigation controls the interconnection between the content elements. The techniques for adaptive navigation controls are direct guidance, link sorting, link hiding, link annotation, link generation and map adaptation [17].

One of the most prevalent areas of adaptive hypermedia is the Adaptive Educational Hypermedia Systems (AEHS). These are online systems used for teaching and learning of online students [20]. These systems use adaptive hypermedia techniques to adjust the learning contents according to the required knowledge goals. There are three core components of AEHS: content model, instructional model and learner model [21]. The content model deals with the course domain and includes course topics, content levels, learning outcome and details of the tasks performed by learners. The instructional model aims at the pedagogy of the learning system. It uses information from content model and learner model and selects the appropriate content for the learner. The learner model keeps track of information about the learner. It takes the parameters from learner's personality and applies statistical inference about their knowledge level [22]. The personality comprises of profiles and learning styles of students, which deal with different aspects of perceiving and processing information by different people [23]. The major models of learning styles have been identified on the basis of theoretical importance and used in research and development work. The important theories include Visual Auditory, Kinesthetic (VAK) [24], FelderSilverman [25] and Kolb [26] learning style theory.

Adaptable e-learning has been an area of researchers' interest since long time, therefore a number of studies have been proposed. These studies revolve around three important aspects, i.e., content authoring, pedagogical considerations and user modeling approaches. Content authoring tools are specialized software applications used for aligning and arranging learning contents. There are large number of content authoring tools which includes TANGOW [27], AHA [28], AMAS [29], GRAPPLE [30], and MOT [31]. All these tools are diverse in nature therefore the selection of right tool for the right subject requires detailed analysis and testing. The matching with subject domain and requirement of specific group of learners are important issues. Some tools are complicated and difficult to use by non-technical users [32]. The pedagogical designs in authoring tools are also difficult to implement [33]. Due to importance of online teaching methods the pedagogy has been an important consideration for adaptive e-learning [34]-[35]. Although every tool define a set of pedagogical rules to present adaptive content, the pedagogy of e-learning varies due to institutional policies, domain of study and assessment criteria. A predefined pedagogy may not be suitable for every program of study therefore there is a need of a generalized model which can be adapted to institutional polices.
The modeling of the user activities is another important consideration of the researchers in adaptable e-learning. There are two important techniques that may be used to implement learner model: knowledge-based and behavioral-based [36]. These approaches are used to generate adaptation rules for the generation of adaptive content. The knowledge-based technique comprises of structured and unstructured information about the students. The initial data for knowledge-base is obtained through questionnaires, user profile, preferences and learning styles [37]. The behavioral-based is the range of actions and reactions of students during interaction with the learning system. The behavior modeling may be implemented through overlay and perturbation model [38]. Both the knowledge-based and behavioral-based techniques have been considered for the development of adaptive e-learning systems [39]-[43], yet they differ in domain knowledge, complexity, pedagogy and user interface technology. They also diverge in practice, the range of sophistication, and level of details. Most of the adaptive e-learning systems and models are being developed and practiced for specialized domains mainly in higher learning institutions. The adoption of such adaptable elearning models is not easy due to variety of issues such as lack of instruction design models for e-learning [12], nonavailability of localized contents, power failure [44], Internet bandwidth [45], English language competency level [46] and different norms among teaching and learning communities. Therefore, there is a dire need and growing demand to develop a generalized adaptable learner model, which can easily be replicated in a local environment. This motivation encourages us to present a learner model for adaptable e-learning that not only complies with international e-learning standards like IEEE LOM \& IMS LIP but is also suitable for locally available ICT environment in order to fulfill needs of local learners.

\section{PROFILES AND PREFERENCES OF LOCAL LEARNERS}

E-learning can be more effective if it is adapted to the needs of learners. Therefore, before developing the e-learning framework, local learners are investigated to determine their ICT capacity and preferences about adaptable e-learning. A questionnaire is developed and validated through consultation of experts from education and technology. The questionnaire was distributed among the four hundred students of the Bachelor of Science in Computer Science BS (CS) and the Post Graduate Diploma in Computer Science PGD (CS). The CS program is selected because its students have the competency in using and comprehending computer applications. Furthermore, the CS programs have a flavor of e-learning mode of education in selected courses with representation in urban, semi urban and rural areas of the country. These responses are analyzed using SPSS and results are given below.

\section{A. Demographics}

The demographic results show that $80.6 \%$ of respondents are male and $19.4 \%$ are female with majority of students in the age group of 21-30 years as shown in Table 1 . The majority of the respondents $(73.4 \%$ ) are living in urban areas, whereas 9.9 $\%$ in semi-urban, and $16.7 \%$ in rural areas. 
TABLE I. STUdENTS’ Demographic Profile

\begin{tabular}{|l|l|l|}
\hline Variable & Frequency & \% Frequency \\
\hline Gender & 203 & 80.6 \\
\hline Male & 49 & 19.4 \\
\hline Female & 252 & 100 \\
\hline Total \\
\hline Age Group & 17.9 \\
\hline Less than 21 & 45 & 71.4 \\
\hline $21-30$ & 180 & 8.3 \\
\hline $31-40$ & 21 & 2.4 \\
\hline More than 40 & 6 & 100 \\
\hline Total & 252 & 73.4 \\
\hline Location & 185 & 9.9 \\
\hline Urban & 25 & 16.7 \\
\hline Semi-urban & 42 & 100 \\
\hline Rural & 252 & 71.4 \\
\hline Total & 28.6 \\
\hline Program of Study & 180 & 100 \\
\hline BS (CS) & 72 & \\
\hline PGD (CS) & 252 & \\
\hline Total &
\end{tabular}

\section{B. Accessibility to ICT Devices}

The analysis of respondents on accessibility to ICT devices is given in Table 2. The results show that computers and laptops are most accessible among all devices. However, these are slightly less accessible in rural and semi urban areas as compared to urban areas. The latest devices such as iPad are rarely used by the respondents. The interesting fact is that TV and Radio are found to be more in use in semi urban areas. However, their usage for education is less than that of computers and laptops. The analysis reveals that ICT devices are highly accessible to the local learners, which is an encouraging sign for the implementation of e-learning. The significant level ( $p$ value) for computer/laptop is less than 0.05 which rejects the null hypothesis when the hypothesis is true. Similar analysis is found in cases of mobile phones, CD/DVD player and TV/Radio. It reveals that strong association exists between the location and accessibility variables. The p-value is greater in case of iPad but has no significance because iPad is rarely used by the respondents as given in Table 2 .

\section{Accessibility to Internet}

The analysis of respondents' accessibility to Internet is given in Table 3. The results show that the broadband Internet connection at home is the highest available facility with a mean value of 3.71. The Internet in an institution/office and via mobile is found another closer option. Internet at cafe and Internet dial up options obtain low scores. It means that students can participate in e-learning activities with ease because of Internet availability at their homes and offices. The p-value analysis shows that the broadband Internet connection has the highest significant level. It implies that the strong association does not exist between the location and Internet variables and Internet is available in urban, semi-urban and rural areas of the country.

\section{Adaptable E-learning Preferences}

The adaptable e-learning preferences have been investigated to determine the opinion of students about personalized learning with special assistance to weak learners. The analysis of respondents on adaptable preferences is given in Table 4. The respondents prefer locally prepared material in simple English language. They want freedom and control, while browsing educational contents and participating in online activities. They also want format of contents which matches their learning styles. The results further reveal that the respondents prefer adaptable features to expedite their learning skills. The majority of learners want personalized learning with their favorite format of contents. They want special assistance during online education. The mean values have shown significant preferences of students towards adaptable e-learning.

The results are quite encouraging as accessibility to ICT devices and Internet connection are on a high scale. Most of the students have computers and laptops with broadband Internet connection. There is an enormous potential for the growth of online education as public infrastructure is available to support modern distance learning mode. The results reveal us the need for localized and adaptable e-learning model.

\section{TABLE II. ACCESSIBILITY TO COMMONLY USED ICT DEVICES BY LOCATION}

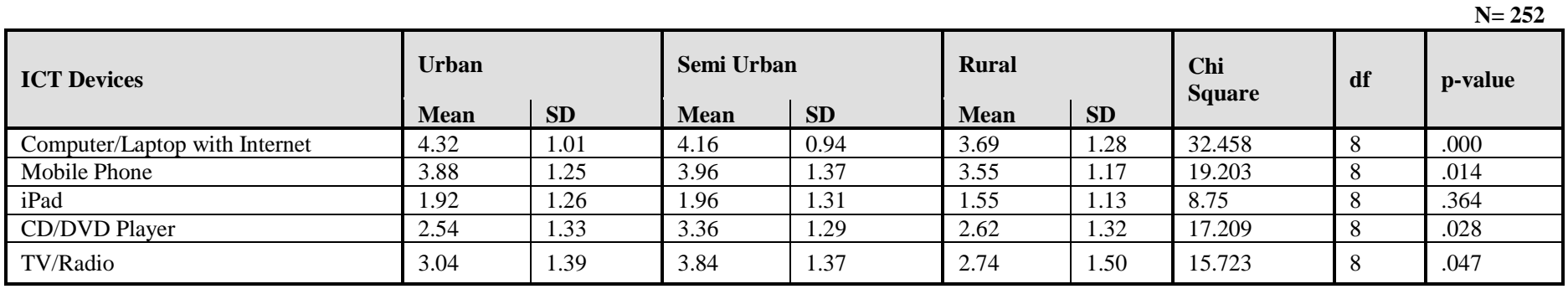

TABLE III. INTERNET ACCESS

\begin{tabular}{|l|l|l|l|l|l|}
\hline Internet Connectivity Options & Mean & SD & Chi-Square & Df & p-value \\
\hline Internet Dialup at home & 2.62 & 1.54 & 19.489 & 8 & .012 \\
\hline Broadband (e.g.DSL) at home & 3.71 & 1.40 & 46.429 & .000 \\
\hline Internet at institution/office & 3.18 & 1.36 & 6.624 & 8 & 8 \\
\hline Mobile Internet & 2.97 & 1.32 & 5.073 & .578 \\
\hline Wireless Internet & 3.15 & 1.48 & 17.184 & 8 & 8 \\
\hline Internet at café & 2.01 & 1.21 & 13.49 & .750 \\
\hline
\end{tabular}


TABLE IV. ADAPTABLE E - LEARNING PREFERENCES

\begin{tabular}{|c|c|c|}
\hline Adaptable E-learning Preferences & Mean & SD \\
\hline Course materials should be in simple language & 4.15 & 1.00 \\
\hline E-course materials should match the learning style & 4.00 & 1.00 \\
\hline $\begin{array}{l}\text { Instructions should be available on different medium of instructions (e.g. Text, multimedia, Radio, TV, Mobile, and Internet } \\
\text { etc.) }\end{array}$ & 3.94 & 1.08 \\
\hline The learning content which is presented as per my favorite format improve my learning & 3.99 & 0.94 \\
\hline I need special academic assistance during online education & 4.10 & 1.05 \\
\hline
\end{tabular}

\section{Proposed Adaptable Learner Model}

In this section, our proposed adaptable learner model is being presented. The proposed model is based on the findings of survey conducted to investigate the profiles and preferences of the local learners as presented in Section III. The proposed adaptable learner model, as shown in Fig. 1 can be conceptualized in the perspective of layered technology of software engineering with knowledge as the foundation layer. This layer glues personality, domain and pedagogy layers with the blend of technology interface. It enables the functionality of key process areas for smooth delivery of course instructions, contents and learning activities. The key process areas coordinate gradually to increase the knowledge level of learners and ensure the quality of learning.

If the knowledge and software engineering models are interwoven, the adaptable e-learning can be made flexible and interactive in nature. It helps to maximize the students' participation in a particular course (domain of learning). It is, therefore, a combination of both education and technology, integrated for the purpose of knowledge transfer through teacher specified domain (content) and pedagogy (learning activities) using the interface of delivery and communication.

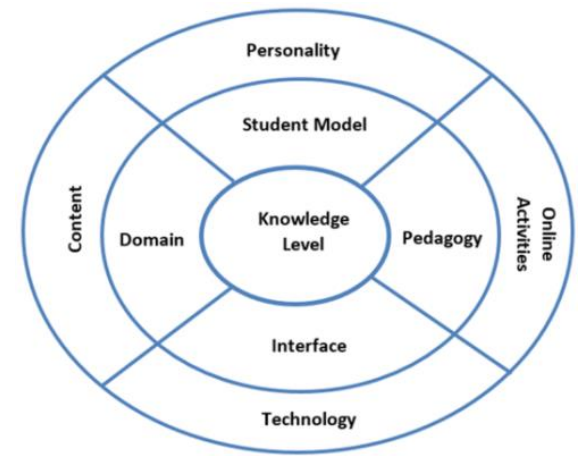

Fig. 1. Layered approach of proposed adaptable e-learning model.

The student model plays a pivotal role in knowledge transfer and the use of ICT for teaching and learning processes. Its goal is to improve the knowledge level of learners by using the adaptable contents. The components of each layer are given in Fig. 2 and are described below.

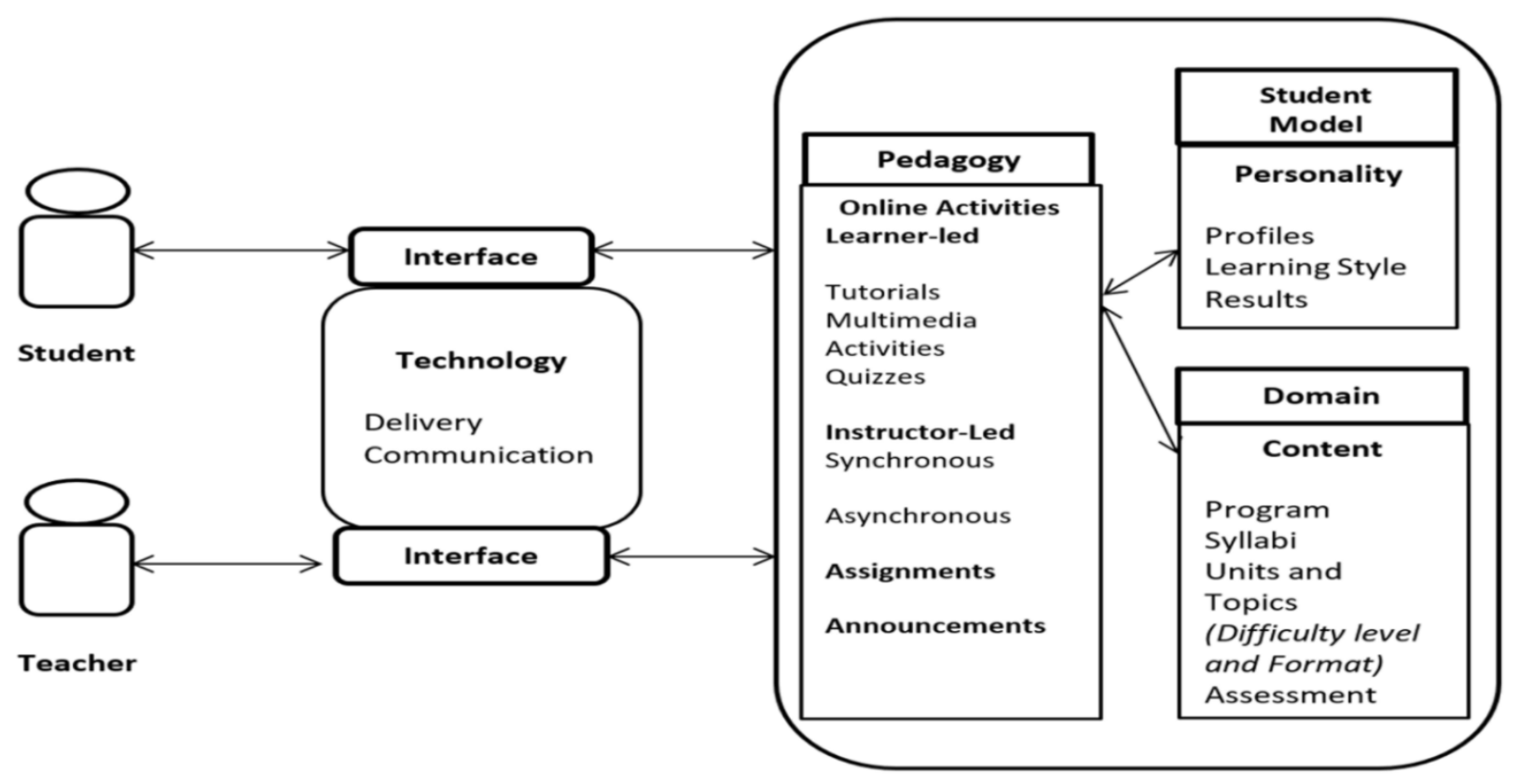

Fig. 2. Proposed learner model of adaptable e-learning. 


\section{A. Domain Model}

The Domain Model is the main component of our proposed adaptable e-learning model. It is composed of information about program, syllabi (curriculum sequence) and courses. Each course is divided into coherent concepts referred to as unit, which is further divided into related topics and sub-topics. The metadata is adopted from IEEE LOM metadata standard for learning objects [47]. Each unit has been tailored up to three levels of knowledge depth. The beginner level comprises of the basic concepts of the topic. The moderate level defines the topic in more detail and the advance level covers the expert domain knowledge. The granularity level is defined on the topic level which is the finest level of granularity in terms of size and concepts and can be re-used in other courses as shown in Fig. 3. Additionally, for each difficulty level, three formats of the contents are proposed to match with visual, auditory and kinesthetic learning styles.

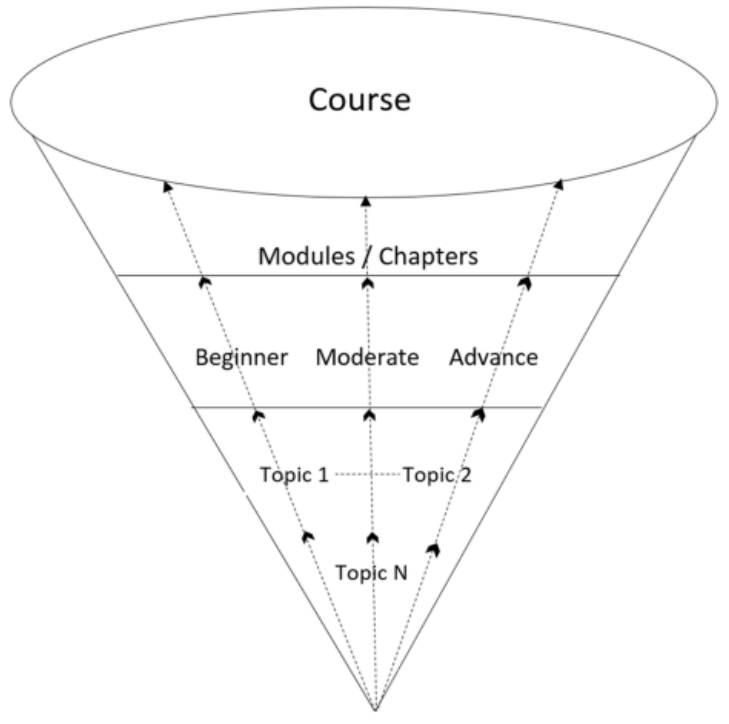

Fig. 3. Granularity of adaptable content.

These formats include tutorials, multimedia instructions and activities as shown in Fig. 4. The tutorial is an instructional lesson that explains the key concepts of a topic. It is consist of a series of content-pages linked via hyperlinks that gradually develop the concepts. The tutorials are authored in the form of webpages connected through hyperlinks using authoring tool of MOODLE LMS. They are used to facilitate students with visual learning style. Multimedia instructions are developed through a combination of text, audio, video and animation. Multimedia electronic courseware is used to develop hypermedia instructions to assist students with visual and auditory learning styles. The multimedia components are assembled in a Shock Wave Flash (SWF) file using Flash Macromedia tool. The text, audio, video, image, table, figure, and animation are synchronized in SWF files and are uploaded by using MOODLE LMS. The activities (such as quizzes and assignments) are developed to let the student learn concepts by doing exercises and assignments. It enables students to apply actions on various concepts and situations by using their critical thinking ability. These activities are used to facilitate students with kinesthetic learning styles. The activities are also compiled as webpages using MOODLE LMS authoring tools.

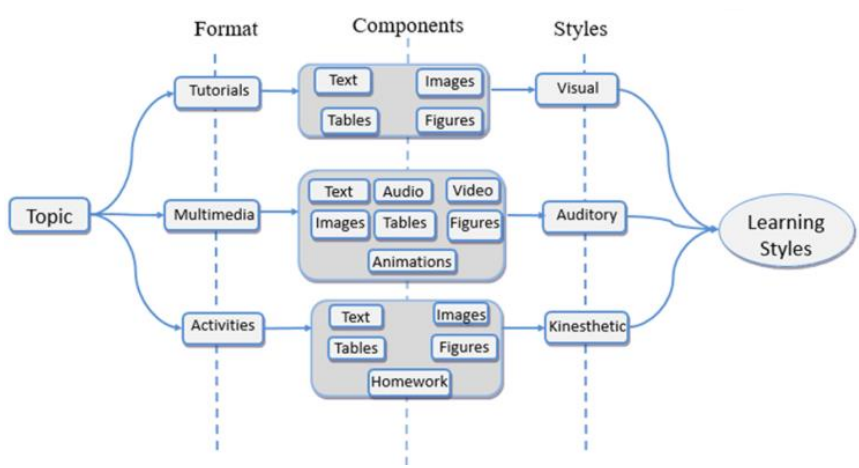

Fig. 4. Format of contents and learning styles.

\section{B. Student Model}

The student model collects information related to leaners as shown in Fig. 5. The metadata is adopted from IMS Learner Information Package [48]. The profiles are comprised of personal information, location and profession. The device accessibility determines the availability of commonly used ICT devices to local learners. The Internet access determines the availability of Internet to the local learners. The preferences of learners are determined to find out their level of inclination towards technology based learning. The performances are based on the evaluation results of pop-up quizzes. The learning style captures information about visual, auditory and kinesthetic learning styles.

The assessment quizzes are developed with content levels for each unit of the course. The stereotypes are defined on the basis of student's achievements in quiz results (following university grading system) as shown in Table 5:

Students who achieve the quiz percentage less than 60 are categorized as beginner with knowledge level, $K=1$. The other category $\mathrm{K}=2$ is of moderate learner with percentage in quiz greater or equal to 60 and less than 80 . The advance level of learners, $K=3$ have percentage greater or equal to 80 . The learners who acquire the knowledge level $\mathrm{K}=3$ can move to the next level of topic as per algorithm. The information of student model is stored at backend in MySQL database of MOODLE LMS.

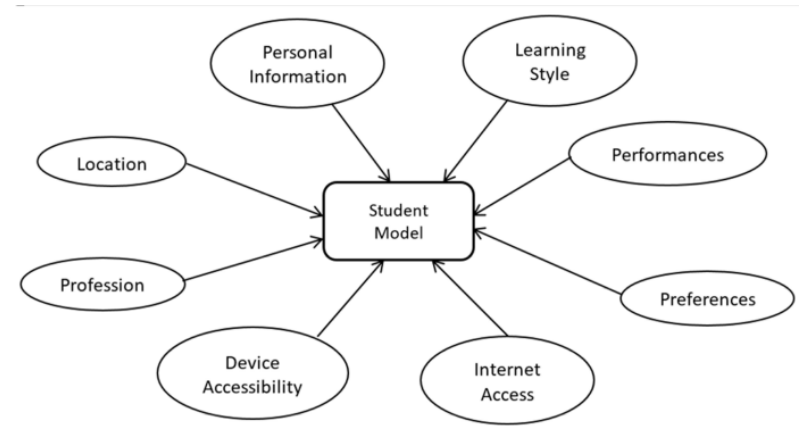

Fig. 5. Student model.

TABLE V. STUDENT'S STEREOTYPE

\begin{tabular}{|l|l|l|}
\hline Stereotype & Interval & Knowledge \\
\hline Beginner & $\mathrm{K}(\mathrm{X})<60$ & $\mathrm{~K}=1$ \\
\hline Moderate & $60 \leq \mathrm{K}(\mathrm{X})<80$ & $\mathrm{~K}=2$ \\
\hline Advance & $80 \leq \mathrm{K}(\mathrm{X}) \leq 100$ & $\mathrm{~K}=3$ \\
\hline
\end{tabular}




\section{Pedagogy}

The course pedagogy is hybrid and composed of both the learner led and the instructor led online activities blended with face to face program workshop. The course calendar, outline and contents and assessments are uploaded by the instructor. The instructor support is available to the students in the form of synchronous online tutorial sessions and asynchronous discussions using forum under instructor led mode. The announcements are made from time to time during the semester. The learner interface is customized for learners to participate in adaptable e-learning activities under learner led mode. The orientation of adaptable e-learning methodology is given during the orientation workshop. The program workshop is arranged in the mid of the semester as a supplement in order to take additional tutorial classes. Both workshops are face-toface and part of the program pedagogy.

\section{Algorithm for Adaptable Content Presentation and Navigation Control}

The proposed leaner model utilizes the information stored about each learner to decide content presentation and navigation control. The proposed algorithm shown in Fig. 6 is used to decide the presentation of contents and learning activities. The index $\mathrm{i}$ indicates the unit number (or chapter number) and index $\mathrm{j}$ indicates the content level. The index $\mathrm{k}$ indicates the knowledge level of learners. Every topic starts with the beginner level content of a unit/chapter that is provided in three formats as discussed in previous section. The presentation of contents is followed by an evaluation quiz to assess knowledge level of students. The quiz results are used to assess the achieved knowledge level of learners (beginner, moderate or advance). If the learners achieved knowledge level is beginner or moderate then he/she is required to browse the content and appear in the quiz again until he/she achieves the advance level of knowledge. After completing three levels of knowledge of a unit, learner can move to next unit. Note that the adaptation rules (Steps 6 and 7 of the algorithm) control the display of pages from the domain model using student's assessment data from the student model. The navigation control uses the link enabling and disabling customization in MOODLE to control the learning activities.

\section{E. Interface}

The Interface is a platform for learners and instructors to interact with adaptable e-learning system. The prototype of proposed research model is implemented using MOODLE Learning Management System (LMS). MOODLE is an open source LMS based on Hypertext Preprocessor (PHP) server based technology which uses MySQL database at the backend. The teacher interface is customized to control the adaptable elearning mechanism. A new file was created in MOODLE content directory comprising of the proposed algorithm. This algorithm is called by extending the existing presentation and navigation functionality. Once the contents are uploaded by the teacher the algorithm controls the sequence of activities as per rules discussed in content presentation method. The selected screen shot of the homepage is shown in Fig. 7 and it comprises of virtual class room (tool for synchronous communication), links of news \& discussion forums, assignments and course outlines.



Fig. 6. Algorithm for adaptable content presentation.

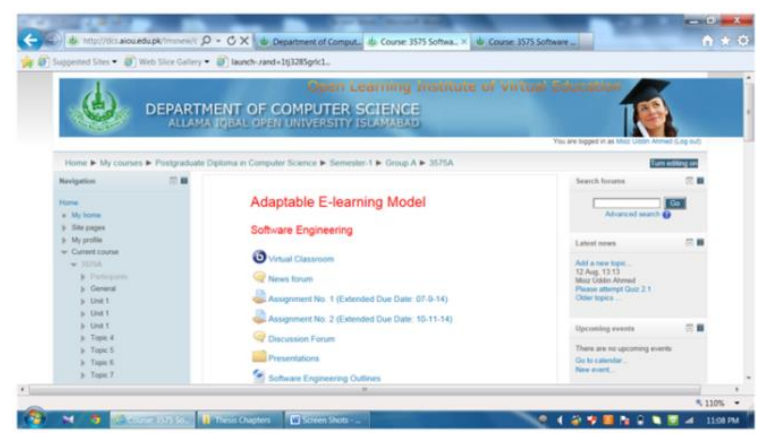

Fig. 7. A course homepage under adaptable e-learning.

\section{EXPERIMENTAL RESULTS}

The adaptable e-learning model is tested on software engineering course of PGD (CS) program offered at AIOU. There were 78 students enrolled from different cities of the country who participated in learner-led and instructor-led activities. The results show that the performance of students improves significantly as he/she progresses in the said course as shown in Fig. 8.

The analysis reveals that the average marks in first attempt in each quiz are less than the average marks in all (total number of attempts in each quiz) and the last attempt. It is due to the reason that the first attempt of quiz was started with the beginner level of each topic where students had little knowledge related to the topic. They repeated the lessons and improved their percentage in the second attempt of each quiz. The process continued till they achieved the highest marks in last attempt of each quiz. The overall result comparison was made with the previous groups of the same course and shown in Fig. 9. 
The students of adaptable e-learning batch 5 have shown better performance as compared to the previous batches. In this batch, $13 \%$ of the students got A+ grade which is second highest in the last five years results. The majority of students (41\%) fall between $\mathrm{B}$ or $\mathrm{C}$ grades which is also higher in percentage as compared to the previous groups. The absent (failure) rate has also dropped to $34 \%$. This analysis is encouraging as students' learning has improved through the use of proposed adaptable e-learning model.



Fig. 8. Average marks in first, all and last attempts.

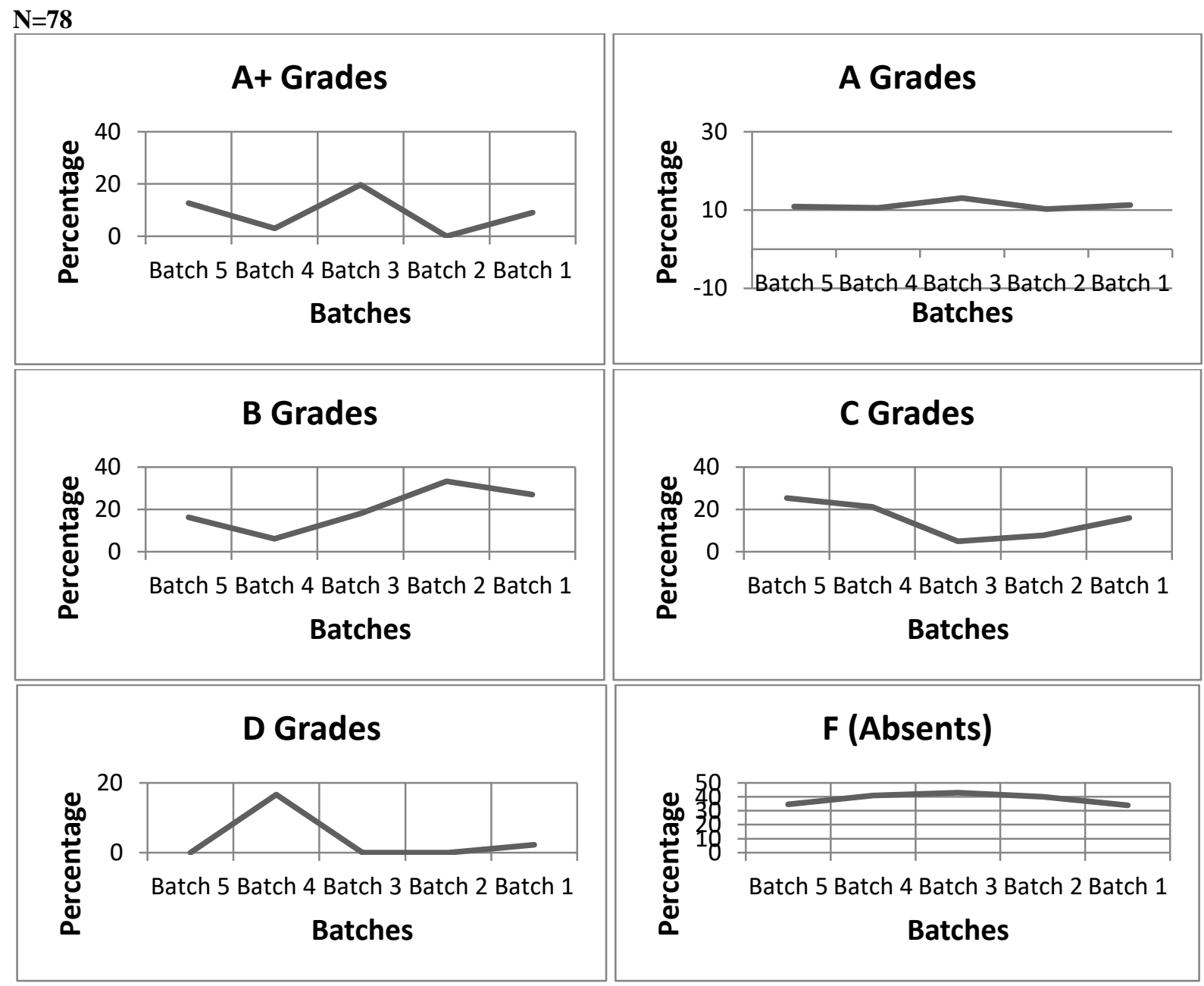

Fig. 9. Overall result comparison from the previous groups.

\section{CONCLUSION}

An adaptable e-learning model has been proposed in this paper. The compliance with e-learning standards has been assimilated for the wider acceptance among the local academic community. A survey of local learners is conducted to determine the profiles, preferences and learning styles. The local parameters are incorporated to fulfill the learning needs and styles. The model is based on domain, pedagogy, technology interface and local learners' profiles. The model has been implemented on a course with development of localized, standardized e-learning contents and their delivery over the local ICT infrastructure under the unique program pedagogy. The examination results reveal that the proposed adaptable e-learning model has a significant impact on the performance of students. The performance of the class has improved overall as compared to previous batches of the same course and the failure rate has also dropped sheer.

Future work will deal with the development of academic repository of different formats of digital contents associated with the difficulty levels of knowledge. The development of 
question databank and creation of adaptive test shall be a part of the future work. The decision support system shall also be linked with the student participation and performance so that the system may advise students on the basis of their requirements and needs. This research provides a common ground for the future research based on adaptive and adaptable e-learning.

\section{ACKNOWLEDGEMENT}

This research work was made possible through the feedback and support from faculty, staff and students of AIOU. We are also thankful to internal and external reviewers for their comments and suggestions.

\section{REFERENCES}

[1] G. Puri, "Critical success Factors in e-Learning -An Empirical Study", International Journal of Multidisciplinary Research, vol. 2, no. 1, pp. 149-161, 2012.

[2] S. R. Harandi, "Effects of E-learning on Students' Motivation", Procedia-Social and Behavioral Sciences, vol. 181, pp. 423-430, 2015

[3] P.F. Ellis, and K. D. Kuznia, "Corporate E-learning Impact on Employees", Global Journal of Business Research, vol. 8, no. 4, pp. 1$15,2014$.

[4] J. L. Moore, C. D. Dean, and K.Galyen, "E-Learning, Online learning, and Distance Learning Environments: Are they the same?" Journal of Internet and Higher Education, vol. 14, pp. 129-135, 2011.

[5] J. Wang, D. Solan and A. Ghods, "Distance Learning Success: A perspective from Socio-Technical Systems Theory", Behaviour \& Information Technology, vol. 29, no. 3, pp. 321-329, 2010

[6] H. Rana, Rajiv, M. Lal, "E-learning: Issues and Challenges", International Journal of Computer Applications, vol. 97, no. 5, pp. 2024, 2014

[7] P. Mohammed and P. Mohan, "A Case Study of the Localization of an Intelligent Tutoring System", Paper presented at second International Workshop on Learning Technologies for the Developing World in conjunction with AIED 2013, Memphis, USA, 2013.

[8] J. Cos, R. Toval, J. L. Fernández-Alemán, J. M. Carrillo-de-Gea and J. Nicolas, "Internationalization Requirements for E-learning Audit Purposes", In Global Engineering Education Conference, 2012

[9] P. Ardimento, N. Boffoli, N. Convertini, and G. Visaggio, ed. "Decision Table for Adaptive E-learning Systems in Education in a Technological World", Communicating Current and Emerging Research and Technological Efforts. 127-134, A. Méndez-Vilas, 2011.

[10] P. Brusilovsky, "Adaptive Hypermedia, an Attempt to Analyze and Generalize. Lecture Notes in Computer Science", Springer- Verlag, Berlin, Germany, pp. 288-304, 1996.

[11] B. Radenkovic, M. Despotovic, Z. Bogdanovic, and D. Barac, "Creating Adaptive Environment for E- learning Courses", Journal of Information and Organizational Sciences, vol. 33, no. 1, pp. 179-189, 2008

[12] K. Daud, "Development of Multimedia Instruction Objects for Delivery in a Localized E-Learning Environment", Dissertation Defense, Allama Iqbal Open University, Islamabad, 2009

[13] N. Sangi, "Access Strategy for Blended E-learning: An AIOU Case Study", Journal of the Research Center for Educational Technology (RCET), vol. 5, no. 2, pp. 75-91, 2009

[14] F. Chukwunonso, R. B. Ibrahim, A. B. Selamat, A. Idama, and W. A. Gadzama, 'The Impact of the Internet and the World Wide Web on Distance and Collaborative Learning", In Eighth International MultiConference on Computing in the Global Information Technology, Nice, France, 2013

[15] G. Woodill, "Where is the Learning in E-learning?", Educational Psychology Interactive, Valdosta, GA, 2004.

[16] J. Vélez, R. Fabregat, S. Nassiff, J. Petro, and A. Fernandez, "Integrated User Model in Adaptive Virtual Learning Environment", World
Conference on E-Learning in Corporate, Government, Healthcare and Higher Education, Las Vegas, United States, pp. 3275-3284, 2008.

[17] P. Brusilovsky, and P. Miller, ed. Course Delivery Systems for the Virtual University, "Access to Knowledge: New Information Technologies and the Emergence of the Virtual University", Amsterdam: Elsevier Science, pp. 167- 206, 2001

[18] A. Alla, "Advances in Intelligent Tutoring Systems: Problem-Solving Modes and Model of Hints", International Journal of Computers, Communications \& Control, vol. 1, pp. 48-55, 2007.

[19] H. Mohamed, T. Bensebaa, and P. Trigano, "Developing Adaptive Intelligent Tutoring System based on Item Response Theory and Metrics", International Journal of Advanced Science and Technology, vol. 43, pp. 1-14, 2012.

[20] P. Brusilovsky, "Developing Adaptive Educational Hypermedia Systems: From Design Models to Authoring Tools", In Authoring tools for advanced technology Learning Environments, Springer Netherlands, pp. 377-409, 2003

[21] S. Oxman, and W. Wong, "Adaptive Learning Systems", [White Paper], DV X Innovations, DeVry Education Group, Integrated Education Solutions, 2014, Available online at: from http://snapwiz.com/wpcontent/uploads/2014/03/DVx_Adaptive_Learning_White_Paper.pdf

[22] V. Shute, and B. Towle, “Adaptive E-learning", Educational Psychologist, vol. 38, no. 2, pp. 105-114, 2003

[23] H. Pashler, M. McDaniel, D. Rohrer, and R. Bjork, "Learning Styles: Concepts and Evidence", Psychological Science in the Public Interest, vol. 9, no. 3, pp. 105-119, 2008.

[24] S. Gholami, and M. S. Bagheri, "Relationship between VAK Learning Styles and Problem Solving Styles regarding Gender and Students' Fields of Study", Journal of Language Teaching and Research, vol. 4, no. 4, pp. 700-706, 2013

[25] R.M. Felder and L.K. Silverman, "Learning and Teaching Styles in Engineering Education", Journal of Engineering Education, vol. 78, no. 7, pp. 674-681, 1998.

[26] D.A. Kolb, 1984. Experiential Learning: Experience as the Source of Learning and Development, New Jersey, Prentice-Hall, Englewood Cliffs, 1984.

[27] R. M. Carro, E. Pulido, and P. Rodríguez, "Adaptive Internet-based learning with the TANGOW system", In Computers and Education in the 21st Century, Springer Netherlands, pp. 127-135, 2000.

[28] P. De Bra, , N. Stash, D. Smits, C. Romero, S. Ventura, "Authoring and management tools for adaptive educational hypermedia systems: The AHA! case study", Studies in Computational Intelligence, vol. 62, pp. 285-308. Springer, 2007

[29] C. Gaffney, O. Conlan,, and V. Wade, "The amas authoring tool 2.0: A ux evaluation", In Proceedings of the 25th ACM conference on hypertext and social media, pp. 224-230, 2014.

[30] M. Hendrix, P. De Bra, M. Pechenizkiy, D. Smits, and A. Cristea, "Defining adaptation in a generic multi layer model: CAM: The GRAPPLE Conceptual Adaptation Model", In European Conference on Technology-Enhanced Learning EC-TEL., Maastricht, The Netherlands, 2008.

[31] A.Cristea, and C. Stewart, "Authoring of Adaptive Hypermedia. Advances in Web-Based Education: Personalized Learning Environments", Information Science Publishing, 2004.

[32] D. Vassileva, B. Bontchev, B. Chavkova, and V. Mitev, "Software construction of an authoring tool for adaptive e-learning platforms", In Fourth Balkan Conference in Informatics, Thessaloniki, Greece, 2009.

[33] M. Harrigan, M. Kravcik, C. Steiner, and V. Wade, "What do academic users really want from an adaptive learning system?", In Proceedings of the 17th International Conference on User Modeling, Adaptation, and Personalization (UMAP); formerly UM and AH., Trento, Italy, 2009.

[34] C. Watson, F. W. Li, and R. W. Lau, "A pedagogical interface for authoring adaptive e-learning courses", In Proceedings of the second ACM international workshop on Multimedia technologies for distance leaningACM, , pp. 13-18, 2010.

[35] C. Swertz, A.Schmölz, A. Forstner, F.Heberle,, P. A. Henning, A. Streicher,... and S. Zander, "A Pedagogical Ontology as a Playground in 
Adaptive Elearning Environments", In GI-Jahrestagung, pp. 1955-1960, 2013

[36] A. C. Martins, L. Faria, C., V. Carvalho and E. Carrapatoso, "User Modeling in Adaptive Hypermedia Educational Systems", Journal of Educational Technology \& Society, vol. 11, no. 1, pp. 194-207, 2008

[37] O. Bourkoukou, E .El Bachari, and M. El Adnani, "A Personalized ELearning Based on Recommender System", International Journal of Learning and Teaching, vol. 2, no. 2, 2016.

[38] P. L. Nguyen, "A User Modeling System for Adaptive Learning", Journal of Standard Scientific Research and Essays, vol. 2, no. 4, pp. 65-209, 2014

[39] C. Giovannella, and S. Carcone, "A new application to detect "emotional perception and styles" of primary school children, and their evolution with age", In Proceedings of $11^{\text {th }}$ International conference on advanced learning technologies, ICALT 2011, Athens, USA, 2011

[40] D. Vassileva, "Adaptive e-learning content design and delivery based on learning styles and knowledge level", Serdica Journal of Computing, vol. 6, no. 2, pp. 207-252, 2012.

[41] M. Lamia, and L. M. Tayeb, Discovering Learner Styles in Adaptive eLearning Hypermedia Systems, Journal of Universal Computer Science, vol. 19, no. 11, pp. 1522-1542, 2013.
[42] A. Adetunji, and A. Ademola, "A Proposed Architectural Model for an Automatic Adaptive E-Learning System Based on Users Learning Style", International Journal of Advanced Computer Science and Applications, vol. 5, no. 4, 2014.

[43] M. S. Halawa, E. M. R. Hamed, and M. E. Shehab, "Personalized Elearning recommendation model based on psychological type and learning style models", In Intelligent Computing and Information Systems (ICICIS), 2015 IEEE Seventh International Conference, pp. 578-584, 2015

[44] N. Sangi, "Electronic Assessment Issues and Practices in Pakistan: A Case Study", Journal of Learning, Media and Technology, vol. 33, no. 3, pp. 191-206, 2008

[45] A. R. Sajid, and T. Hassan, "ICTs in Learning: Problems faced by Pakistan", Journal of Research and Reflections in Education, vol. 7, no. 1, pp. $52-64,2013$

[46] I. A. Qureshi, K. Ilyas, R. Yasmin, and M. Whitty, "Challenges of Implementing E-learning in a Pakistani University", Journal of Knowledge Management \& E-Learning, 4(3), 310-324, 2012

[47] P. Barker, "What is IEEE Learning Object Metadata/IMS Learning Resource Metadata?", Cetis Standards briefings series, 2005.

[48] LIP, IMS Learner Information Package Specification, 2008. 